\title{
The Volatility Effect in China
}

\author{
David Blitz ${ }^{1} \cdot$ Matthias X. Hanauer ${ }^{1,2}$ Pim van Vliet $^{1}$
}

Revised: 29 March 2021 / Accepted: 6 April 2021 / Published online: 20 April 2021

(c) The Author(s) 2021

\begin{abstract}
This paper shows that low-risk stocks significantly outperform high-risk stocks in the local China A-share market. The main driver of this low-risk anomaly is volatility, and not beta. A Fama-French style VOL factor is not explained by the FamaFrench-Carhart factors, and has the strongest stand-alone performance among all these factors. Our findings are robust across sectors and over time, and consistent with previous empirical evidence for the US and international markets. Moreover, the VOL premium exhibits excellent investability characteristics, as it involves a low turnover and remains strong when applied to only the largest and most liquid stocks. Our results imply that the volatility effect is a highly pervasive phenomenon, and that explanations should be able to account for its presence in highly institutionalized markets, such as the US, but also in the Chinese market where private investors dominate trading.
\end{abstract}

Keywords China A shares $\cdot$ Low risk $\cdot$ Low volatility $\cdot$ Low beta $\cdot$ Minimum variance $\cdot$ Anomaly $\cdot$ Value $\cdot$ Size . Momentum $\cdot$ Profitability $\cdot$ Investments $\cdot$ Smart beta $\cdot$ Low-volatility investing

JEL Classification $\mathrm{G} 11 \cdot \mathrm{G} 12 \cdot \mathrm{G} 14$

\section{Introduction}

This paper shows that there exists a strong, distinct, robust, and investable low-risk anomaly in the China A stock market. The low-risk anomaly is the empirical result that the relation between risk and return is not positive, as predicted by theoretical models, but flat, or even inverted. This phenomenon has been extensively documented for the US and other stock markets, and in this paper we extend this result to the China A-share market. The novel Chinese market offers a rare opportunity for out-of-sample testing, and allows us to examine whether previously reported relations between the low-risk factor and other asset pricing factors are robust. It may also shed a new light on explanations for the anomaly,

Matthias X. Hanauer

m.hanauer@robeco.com

David Blitz

d.c.blitz@ robeco.com

Pim van Vliet

p.van.vliet@robeco.com

1 Robeco Quantitative Investments, Rotterdam, The Netherlands

2 Technical University of Munich, Munich, Germany since trading on the Chinese stock exchanges is dominated by local, private investors, unlike the US market which is highly institutionalized. In the remainder of this introduction, we first review the low-risk anomaly, then discuss prior studies for the China A market, and finally outline our contributions to the existing literature.

The Capital Asset Pricing Model (CAPM) and its various extensions predict a positive relation between risk and return, but the very first empirical asset pricing studies in the nineteen seventies already found evidence for a low-risk anomaly, e.g., Black et al. (1972), Miller and Scholes (1972), Fama and MacBeth (1973), and Haugen and Heins (1975). Two decades later, Fama and French (1992) unequivocally conclude that, contrary to the predictions of the CAPM, market beta is unpriced in the cross-section of stock returns. Despite this finding, the Fama and French $(1993,2015)$ asset pricing models retain the classic CAPM relation between market beta and return, and merely add additional factors to account for other anomalies documented in the literature.

Blitz and van Vliet (2007) take a fresh look at the lowrisk effect and find that, over their 20-year sample period, the relation between risk and return is not merely flat, but even outright inverted. They also find that volatility rather than beta is the main driver of the anomaly, and that the 
effect is not only present in the US equity market, but also in the European and Japanese equity markets. Blitz et al. (2013) document similar results for emerging equity markets-which did not include local Chinese stocks at that time. More evidence is provided by, among many others, Baker et al. (2011), Baker and Haugen (2012), Frazzini and Pedersen (2014), and Walkshäusl (2014). A parallel stream of literature examines the empirical performance of the theoretical minimum-variance portfolio and also finds clear evidence for the existence of a low-risk anomaly; see Haugen and Baker (1991, 2010), Clarke et al. (2006, 2011), and Buehlmaier and Wong (2020). Another related stream of literature finds a low-risk anomaly for risk measured over very short-term lookback periods, most notably Ang et al. (2006, 2009), who consider past 1-month idiosyncratic volatility (iVol), and Bali et al. (2011), who use the maximum daily return over the past 1 month (MAX). We refer to Russo (2016) and Blitz et al. (2020b) for a comprehensive overview of the literature on the low-risk effect.

Trading in local China A shares takes place on the stock exchanges of Shanghai and Shenzhen since the early nineties. The Chinese A-share market is characterized by higher volatility, negative skewness and herding. ${ }^{1}$ Initially, the China A market was only accessible to local investors, but over time the market gradually opened up to international investors. An important milestone was reached in 2018, when leading index provider MSCI added China A shares to its flagship emerging markets index, resulting in flows from passive and active investors all over the world into this market. By that time, the China A market had grown to the second largest and most liquid market, after only the US. ${ }^{2}$ A major difference, however, is that whereas the US market is highly institutionalized, the China A-share market is not. Hilliard and Zhang (2015), Han and Li (2017), and Hu et al. (2018) estimate that $80 \%$ of the trading volume on Chinese stock exchanges is from local, private investors.

The literature on the cross-section of stock returns in China is still relatively young but growing and maturing rapidly. Early studies such as Wang and Xu (2004), Wong et al. (2006), and Wang and Di Iorio (2007) find that market beta is not priced in China, which indicates that the low-risk anomaly also exists in China. However, the sample periods used in these studies are relatively short and end already in 2002. More recent evidence is provided by Han et al. (2020) and Long et al. (2019). They document a significant negative impact on returns for market beta and systematic tail risk (beta), respectively, over a twenty-year sample period.

\footnotetext{
${ }^{1}$ For more information on China A-share stock return characteristics see: Su and Fleisher (1999), Seiler et al. (2005), and Tan et al. (2008).

${ }^{2}$ Source: World Bank Development Indicators CM.MKT.LCAP.CD and CM.MKT.TRAD.CD, respectively.
}

Consistent with this finding of an inverse Security Market Line, Chen et al. (2018) find that a minimum-variance strategy in China yields a higher return than the market, while having lower risk. This minimum-variance strategy does involve a significant amount of trading, with an estimated turnover of about $100 \%$ per annum. The iVol anomaly is shown to be present in China by Eun and Huang (2007), Chen et al. (2010), and Cakici et al. (2017), while Cheema et al. (2018) confirm the MAX anomaly for China. However, due to the very short (1 month) lookback period of these strategies, high implementation costs are an even bigger concern here. $^{3}$

Our work is most closely related to Cheung et al. (2015) and Hsu et al. (2018), who examine the general effectiveness of asset pricing factors in China. Both studies document the existence of a low-volatility anomaly, as in Blitz and van Vliet (2007). In addition, they find that the size and value factors are effective in China, but that the momentum, profitability, and investment factors are not. Thus, the evidence for factor investing that emerges from these studies is mixed. Also, the statistical significance, robustness, and distinctness of the low-volatility anomaly in China remain unclear from these studies. Liu et al. (2019) propose a 3-factor model for China, consisting of market, size, and value factors. By using the market factor, this model assumes that market beta is priced according to the theoretical CAPM relation. They find that this model explains the short-term iVol and MAX anomalies, and also the profitability anomaly. In a contemporaneous paper, Jansen et al. (2021) examine the existence of 32 anomalies in the China A share and find that low-risk stocks outperform high-risk stocks for different holding periods, for equal- and value-weighting, for size- and industryneutral sorts, and for state- and non-state-owned enterprises.

This paper adds to the existing literature by thoroughly examining the volatility effect in China. Our study builds upon the Fama-French framework of creating factors in a consistent way and empirically testing them on a like-forlike basis with other factors, following the recommendations of Lewellen et al. (2010). We construct a VOL factor following the Fama-French $2 \times 3$ factor portfolio construction methodology, which ensures that our results are directly comparable to other factors. Fama-French are skeptical towards short-term factors, which require high amounts of turnover, involve market micro-structure concerns, and do not exhibit stable style characteristics. Therefore they do not include fast 1 month price reversal or 12-1 month price momentum factors in their asset pricing models. Moreover, Novy-Marx and Velikov (2016) find that most high-turnover

\footnotetext{
${ }^{3}$ Novy-Marx and Velikov (2016) find that most high-turnover anomalies do not survive after accounting for transaction costs even when designed to mitigate transaction costs.
} 


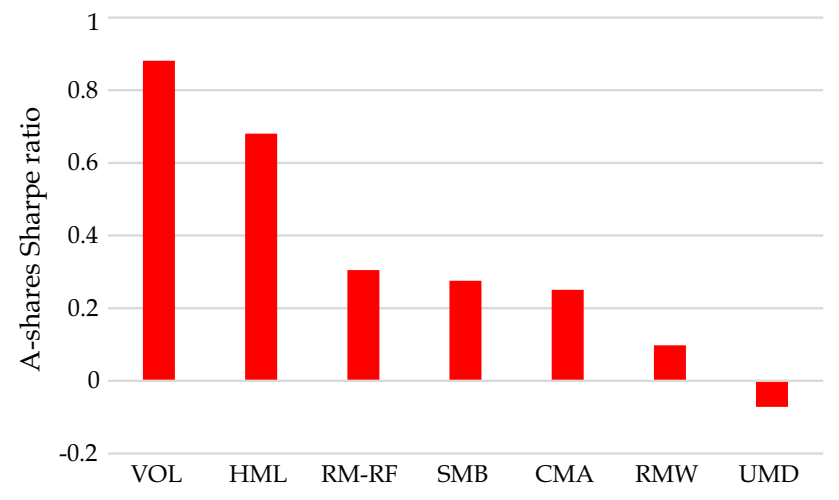

Fig. 1 Factor Sharpe ratios in China, 2000-2018. This figure summarizes the Sharpe ratios of the market (RM-RF), size (SMB), value (HML), profitability (RMW), investment (CMA), momentum (UMD), and volatility (VOL) factors for the Chinese A-share market over the sample period December 2000-December 2018

anomalies do not survive after accounting for transaction costs, and Hou et al. (2020) find that many anomalies disappear after excluding illiquid micro-cap stocks and using value-weighting instead of equal-weighting. To address these concerns, our base-case choice is to measure risk over a 3-year horizon, similar to Blitz and van Vliet (2007), rather than a 1-month horizon. In addition, our sample consists of the largest and most liquid stocks, so micro-cap stocks which are large in number but make up a tiny part of total market capitalization are not included.

Our first contribution is to show that the low-risk anomaly is strongly present in China. Consistent with previous studies on the low-risk effect, we find that the main driver of the anomaly is volatility, rather than market beta. We find very similar results for shorter (up to 1-month) and longer (up to 5-year) volatility estimation periods. The volatility effect is also robust across sectors and persistent over time. A Fama-French style VOL factor shows a higher risk-adjusted premium than each of the other factors in the Fama-French-Carhart model. This is illustrated in Fig. 1.

Our second contribution is to show that the low-risk anomaly in China is a distinct phenomenon. For the US market, Novy-Marx (2014) and Fama and French (2016) argue that the low-risk anomaly is subsumed by profitability and investment factors, but we find that this result does not carry over to the Chinese market. The volatility effect is also not explained by the size and value factors, contrary to what one might expect based on the results of Liu et al. (2019). We also find that the volatility effect in China is uncorrelated with the volatility effect in other markets. The latter result argues against a unified risk-based explanation for the volatility premium. Our results cannot be attributed to investability frictions, since the alpha is also strongly present among the largest and most liquid stocks, and the required turnover is low. This also means that the strategy exhibits good practical investability properties.

The third contribution of our work is that it sheds new light on explanations for the volatility effect. Unlike the US market, which is highly institutionalized, trading on the Chinese stock exchanges is dominated by private investors. A popular explanation for the volatility effect relates to the role of benchmarks as understood in a classical principal-agent setup (Baker et al. 2011). If delegated portfolio managers with leverage constraints are benchmarked against a market index, they will have a rational preference for risky stocks over safe stocks, which can lead to a flattening of the riskreturn relation. Our finding that the volatility effect is also strongly present in a market dominated by private investors indicates that the phenomenon could have multiple drivers. Private investors may be more prone to behavioral biases, as discussed in Blitz et al. (2014), or overpay for risky stocks because of their lottery-ticket features, as in Barberis and Huang (2008) and Bali et al. (2017). However, it can also not be ruled out that, despite not being benchmarked directly, private investors aim to outperform other investors and therefore have a relative performance objective, similar to institutional investors.

\section{Data and methodology}

Our sample comprises China A stocks starting from November 2000 until December 2018. At the end of every month, we identify all constituents of the MSCI China A Onshore Index and the MSCI China A Onshore Investable Market Index (starting in December 2004) for that particular month. The two indices comprise only securities listed on the Shanghai and Shenzhen exchanges. Stocks that are included in both indices are only included once. According to MSCI, these stocks represent all investable large-, midand small-cap securities and cover approximately $99 \%$ of the market's free-float adjusted market capitalization. We only require stocks to have valid market capitalization data to be included. The resulting universe consists of approximately 1200 stocks on average; the actual number ranges between about 200 and 2200 over time. These numbers are considerably smaller than the total number of listed A shares, which varies between about 1050 and 2800 over our sample period. By excluding the hundreds of stocks which together make up less than $1 \%$ of total market capitalization, we avoid that our results are distorted by micro-caps (cf., Hou et al. 2020). Although MSCI already conducts investability screens, we mitigate the influence of small-cap stocks further by using value-weighted returns and size breakpoints calculated on large- and mid-cap securities (more details later in this section). 
We gather monthly stock returns in US dollars taking into account dividends, stock splits, and other capital adjustments. ${ }^{4}$ Our first data source for returns and outstanding shares is Interactive Data Exshare. In case this data is not available, we use MSCI return series instead. Alternatively, when neither of these is available, we calculate total returns using daily data from S\&P/IFC. In addition to returns, we gather free-float adjusted market capitalization data from MSCI and fundamental data from Worldscope. To avoid a look-ahead bias we lag Worldscope data by six months. As a proxy for the risk-free rate, we obtain the 1-month US Treasury bill rate from the data library of Kenneth French. ${ }^{5}$ All returns are in US dollars and excess returns are measures as total returns in excess of the 1-month Treasury bill rate.

Similar to Blitz and van Vliet (2007) and Blitz et al. (2013), we calculate the past volatility of a stock by taking the standard deviation of its monthly total returns over the preceding 3 years. In a robustness test, we look at the effects of calculating volatility over shorter or longer lookback periods, and the effects of using daily or weekly instead of monthly data. In addition, we consider beta as a second risk measure. The past beta of a stock is calculated by regressing its monthly excess returns over the past 3 years on the excess returns of the value-weighted universe of all stocks. ${ }^{6}$ We require 36 monthly return observations when calculating volatility or beta. Furthermore, we calculate the book-to-market ratio (common equity divided by market equity), operating profitability (operating profits divided by total assets), asset growth (y-o-y growth rate of total assets), and momentum (past 12-minus-1 month total return) for all available stocks in each month.

At the end of every month, we create value-weighted decile portfolios by ranking stocks on their past 3-year volatility or beta of monthly returns. The top decile contains the stocks with the highest volatility (beta) and the bottom decile the stocks with the lowest volatility (beta). We next calculate for each portfolio the total return in US dollars in excess of the 1-month Treasury bill rate over the subsequent month.

We also construct Fama-French style factor portfolios. The Fama-French approach is characterized by $2 \times 3$ double sorts on size and the target factor. For the US, Fama and French $(1993,2015)$ classify all stocks as either large or

\footnotetext{
${ }^{4}$ Our choice for returns in US dollars is motivated by the international asset pricing literature (cf., Fama and French, 2012, 2017). We do not expect that the currency's choice affects our results as (i) RMB/USD changes affect all stocks equally and (ii) the and RMB/ USD rate is very stable over our sample period.

${ }^{5}$ http://mba.tuck.dartmouth.edu/pages/faculty/ken.french/data_libra ry.html.

${ }^{6}$ Before December 2000, the value-weighted market excess return is obtained from the China Stock Market and Accounting Research (CSMAR) database.
}

small based on the median market capitalization of stocks listed on the New York Stock Exchange. Since NYSE stocks tend to be bigger than Nasdaq stocks, this approach results in a larger size breakpoint than if the entire universe of stocks would be used. For China A shares, we follow a similar approach by every month classifying stocks as either large or small based on the median market capitalization of only the stocks in the MSCI China A Onshore Index (which solely consists of large- and mid-cap stocks). Next, low-, mid-, and high-factor portfolios are created within both size groups using the 30th and 70th percentiles as breakpoints. Following Fama and French (2015), we define the size factor (SMB) as the average of the 9 small portfolios minus the average of the 9 large portfolios in the $2 \times 3$ sorts on size and value, size and profitability, and size and investment. All other factors are the difference between the average return of the two high and the two low factor portfolios for the respective factor criteria. In this way, we construct value (HML), profitability (RMW), investment (CMA), and momentum (UMD) factors based on the respective factor criteria (book-to-market ratio, operating profitability, asset growth, and momentum).

In addition, we construct Fama-French style volatility (VOL) and beta (BETA) factors based on similar $2 \times 3$ sorts. Following Blitz et al. (2020a, b), the only deviation from the standard Fama-French factor construction methodology is that the factors are made beta neutral, by levering up the long leg and levering down the short leg to full-sample markets betas of 1 each. Without beta neutrality, the VOL and BETA factors would have a highly negative beta to the market factor. This beta-neutralization adjustment is analogous to the betting-against-beta methodology of Frazzini and Pedersen (2014).

Rankings on volatility or beta can result in structural sector tilts. Asness et al. (2014) and Baker et al. (2014) show that the low-risk effect exists within sectors and countries, and also across sectors and countries. Since China is a single country, we examine the robustness of our findings by computing the VOL and BETA premiums within each sector. We use the 11 main sectors as defined by the Global Industry Classification Standard (GICS) classification, but merge two sectors with a low number of stocks with related sectors: real estate (GIGS sector code 60) with financials (40), and communication services (50) with information technology (45). Due to the lower number of stocks per sector, the single sector VOL and BETA factors are created based on plain sorts on volatility and beta, still using the 30th and 70th percentiles as breakpoints, but without conditioning on size. 
Table 1 Portfolio returns based on past risk measures

\begin{tabular}{|c|c|c|c|c|c|c|c|c|c|c|c|c|}
\hline & D1 & D2 & D3 & D4 & D5 & D6 & D7 & D8 & D9 & D10 & D1-D10 & Univ \\
\hline \multicolumn{13}{|c|}{ Panel A: Volatility deciles } \\
\hline Return & $12.7 \%$ & $12.1 \%$ & $8.3 \%$ & $11.2 \%$ & $11.5 \%$ & $8.3 \%$ & $6.6 \%$ & $6.8 \%$ & $6.0 \%$ & $-0.2 \%$ & $12.9 \%$ & $8.8 \%$ \\
\hline Return comp & $9.6 \%$ & $8.2 \%$ & $4.2 \%$ & $6.6 \%$ & $6.7 \%$ & $3.3 \%$ & $1.3 \%$ & $1.2 \%$ & $-0.1 \%$ & $-6.4 \%$ & $10.6 \%$ & $4.6 \%$ \\
\hline Volatility & $24.8 \%$ & $28.1 \%$ & $28.5 \%$ & $30.3 \%$ & $31.1 \%$ & $31.3 \%$ & $32.5 \%$ & $33.7 \%$ & $34.9 \%$ & $35.1 \%$ & $21.2 \%$ & $29.0 \%$ \\
\hline Sharpe & 0.51 & 0.43 & 0.29 & 0.37 & 0.37 & 0.27 & 0.20 & 0.20 & 0.17 & 0.00 & 0.61 & 0.31 \\
\hline Beta & 0.79 & 0.94 & 0.96 & 1.01 & 1.04 & 1.06 & 1.09 & 1.12 & 1.16 & 1.15 & -0.36 & 1.00 \\
\hline Alpha & $5.7 \%$ & $3.9 \%$ & $-0.2 \%$ & $2.2 \%$ & $2.3 \%$ & $-1.0 \%$ & $-3.0 \%$ & $-3.2 \%$ & $-4.2 \%$ & $-10.4 \%$ & $16.1 \%$ & $0.0 \%$ \\
\hline t-value & 2.55 & 2.34 & -0.16 & 1.26 & 1.27 & -0.65 & -1.55 & -1.60 & -1.95 & -4.01 & 3.69 & 0.00 \\
\hline \multicolumn{13}{|c|}{ Panel B: Beta deciles } \\
\hline Return & $9.4 \%$ & $12.2 \%$ & $13.8 \%$ & $8.4 \%$ & $10.2 \%$ & $8.9 \%$ & $11.3 \%$ & $7.0 \%$ & $7.9 \%$ & $3.2 \%$ & $6.2 \%$ & $8.8 \%$ \\
\hline Return comp & $6.1 \%$ & $8.5 \%$ & $9.5 \%$ & $4.0 \%$ & $5.6 \%$ & $4.0 \%$ & $6.0 \%$ & $1.2 \%$ & $1.9 \%$ & $-3.4 \%$ & $3.5 \%$ & $4.6 \%$ \\
\hline Volatility & $25.7 \%$ & $27.2 \%$ & $29.6 \%$ & $29.7 \%$ & $30.3 \%$ & $31.1 \%$ & $32.6 \%$ & $33.9 \%$ & $34.6 \%$ & $36.5 \%$ & $22.8 \%$ & $29.0 \%$ \\
\hline Sharpe & 0.36 & 0.45 & 0.47 & 0.28 & 0.34 & 0.29 & 0.35 & 0.20 & 0.23 & 0.09 & 0.27 & 0.31 \\
\hline Beta & 0.80 & 0.90 & 0.99 & 0.99 & 1.02 & 1.05 & 1.09 & 1.13 & 1.16 & 1.19 & -0.39 & 1.00 \\
\hline Alpha & $2.3 \%$ & $4.2 \%$ & $5.1 \%$ & $-0.3 \%$ & $1.2 \%$ & $-0.3 \%$ & $1.7 \%$ & $-3.0 \%$ & $-2.3 \%$ & $-7.4 \%$ & $9.7 \%$ & $0.0 \%$ \\
\hline \multirow[t]{2}{*}{ t-value } & 0.88 & 2.38 & 3.18 & -0.21 & 0.73 & -0.19 & 0.89 & -1.43 & -1.26 & -2.74 & 2.06 & 0.00 \\
\hline & $\begin{array}{l}\text { Big } \\
\text { Low Vol. }\end{array}$ & $\begin{array}{l}\text { Big } \\
\text { Neutral }\end{array}$ & \multicolumn{2}{|c|}{$\begin{array}{l}\text { Big } \\
\text { High Vol. }\end{array}$} & $\begin{array}{l}\text { Small } \\
\text { Low Vol. }\end{array}$ & $\begin{array}{l}\text { Small } \\
\text { Neutral }\end{array}$ & \multicolumn{2}{|c|}{$\begin{array}{l}\text { Small } \\
\text { High Vol. }\end{array}$} & VOL & & & \\
\hline \multicolumn{13}{|c|}{ Panel C: $2 \times 3$ Size-Volatility sort } \\
\hline Return & $10.7 \%$ & $6.5 \%$ & \multicolumn{2}{|c|}{$0.9 \%$} & $13.9 \%$ & $11.5 \%$ & \multicolumn{2}{|c|}{$8.8 \%$} & $9.1 \%$ & & & \\
\hline Volatility & $26.5 \%$ & $29.5 \%$ & \multicolumn{2}{|c|}{$34.3 \%$} & $30.5 \%$ & $33.7 \%$ & \multicolumn{2}{|c|}{$36.0 \%$} & $10.3 \%$ & & & \\
\hline Sharpe & 0.40 & 0.22 & & 03 & 0.45 & 0.34 & \multicolumn{2}{|c|}{0.25} & 0.88 & & & \\
\hline Beta & 0.84 & 0.99 & & 13 & 1.00 & 1.10 & \multicolumn{2}{|c|}{1.17} & 0.00 & & & \\
\hline Alpha & $3.2 \%$ & $-2.2 \%$ & & $.1 \%$ & $5.1 \%$ & $1.7 \%$ & \multicolumn{2}{|c|}{$-1.5 \%$} & $9.1 \%$ & & & \\
\hline \multirow[t]{2}{*}{ t-value } & 1.34 & -1.28 & & 87 & 2.16 & 0.67 & \multicolumn{2}{|c|}{-0.50} & 3.72 & & & \\
\hline & $\begin{array}{l}\text { Big } \\
\text { Low Beta }\end{array}$ & $\begin{array}{l}\text { Big } \\
\text { Neutral }\end{array}$ & $\mathrm{B}$ & Beta & $\begin{array}{l}\text { Small } \\
\text { Low Beta }\end{array}$ & $\begin{array}{l}\text { Small } \\
\text { Neutral }\end{array}$ & \multicolumn{2}{|c|}{$\begin{array}{l}\text { Small } \\
\text { High Beta }\end{array}$} & BETA & & & \\
\hline \multicolumn{13}{|c|}{ Panel D: $2 \times 3$ Size-Beta sort } \\
\hline Return & $9.3 \%$ & $7.7 \%$ & \multicolumn{2}{|c|}{$3.1 \%$} & $12.0 \%$ & $12.5 \%$ & \multicolumn{2}{|c|}{$10.0 \%$} & $6.0 \%$ & & & \\
\hline Volatility & $26.2 \%$ & $29.0 \%$ & & $8 \%$ & $30.9 \%$ & $33.7 \%$ & \multicolumn{2}{|c|}{$35.8 \%$} & $10.4 \%$ & & & \\
\hline Sharpe & 0.36 & 0.27 & & .09 & 0.39 & 0.37 & \multicolumn{2}{|c|}{0.28} & 0.58 & & & \\
\hline Beta & 0.84 & 0.97 & & .18 & 0.99 & 1.10 & \multicolumn{2}{|c|}{1.17} & 0.00 & & & \\
\hline Alpha & $1.9 \%$ & $-0.9 \%$ & & $.4 \%$ & $3.2 \%$ & $2.8 \%$ & \multicolumn{2}{|c|}{$-0.4 \%$} & $6.0 \%$ & & & \\
\hline $\mathrm{t}$-value & 0.86 & -0.52 & & 85 & 1.21 & 1.07 & \multicolumn{2}{|c|}{-0.13} & 2.43 & & & \\
\hline
\end{tabular}

This table shows the descriptive statistics for Chinese A-share stocks sorted into portfolios based on past risk measures and the value-weighted universe (Univ) over the period December 2000-December 2018. The returns are in US dollars, value-weighted and in excess of the 30-day T-bill rate. Panel A shows the portfolio deciles sorted on 36-month volatility and panel B when stocks are sorted on 36-month beta. Portfolios are rebalanced on a monthly frequency. To control for differences in volatility, the compounded returns are also shown in Panels A and B. Panels $\mathrm{C}$ and $\mathrm{D}$ show the portfolios sorted on size (market capitalization equity) and risk in line with the standard Fama-French $2 \times 3$ portfolio sorting technique. This procedure produces six value-weight portfolios. The size breakpoint is the MSCI China A Onshore Index (solely large- and mid-cap stocks) median market capitalization but applied to all stocks. The volatility and beta breakpoints are the 30th and 70th percentiles of 36-month volatility and beta within both of these size groups. VOL (BETA) is the equal-weight average of the returns on the two low-volatility (beta) portfolios minus the average of the returns on the two high stock volatility (beta). The VOL and BETA portfolios are made beta neutral, by levering up the long leg and levering down the short leg to full-sample markets betas of 1 each. Only simple returns are shown in Panels C and D

\section{Results}

In our base-case analysis, we sort stocks every month on either their past 36-month volatility or 36-month market beta into value-weighted decile portfolios, and then calculate the excess return of these ten portfolios over the subsequent month. The full-sample performance characteristics for the volatility-sorted portfolios are reported in Panel A of 
Table 2 Controlling for sectors

\begin{tabular}{|c|c|c|c|c|c|c|c|c|c|}
\hline & 10 & 15 & 20 & 25 & 30 & 35 & $40 \& 60$ & $45 \& 50$ & 55 \\
\hline \multicolumn{10}{|c|}{ Panel A: VOL premium within 9 sectors (30-40-30 sort within each sector) } \\
\hline Return & $7.2 \%$ & $6.9 \%$ & $8.6 \%$ & $9.2 \%$ & $17.9 \%$ & $7.3 \%$ & $8.2 \%$ & $3.4 \%$ & $13.9 \%$ \\
\hline Volatility & $24.5 \%$ & $12.7 \%$ & $14.3 \%$ & $14.7 \%$ & $24.3 \%$ & $19.7 \%$ & $20.2 \%$ & $15.5 \%$ & $22.0 \%$ \\
\hline Sharpe & 0.30 & 0.54 & 0.60 & 0.62 & 0.74 & 0.37 & 0.41 & 0.22 & 0.63 \\
\hline Beta & 0.00 & 0.00 & 0.00 & 0.00 & 0.00 & 0.00 & 0.00 & 0.00 & 0.00 \\
\hline Alpha & $7.2 \%$ & $6.9 \%$ & $8.6 \%$ & $9.2 \%$ & $17.9 \%$ & $7.3 \%$ & $8.2 \%$ & $3.4 \%$ & $13.9 \%$ \\
\hline t-value & 1.25 & 2.29 & 2.54 & 2.63 & 3.12 & 1.58 & 1.72 & 0.92 & 2.68 \\
\hline \multicolumn{10}{|c|}{ Panel B: BETA premium within 9 sectors (30-40-30 sort within each sector) } \\
\hline Return & $5.2 \%$ & $3.3 \%$ & $7.0 \%$ & $1.9 \%$ & $18.6 \%$ & $3.6 \%$ & $8.0 \%$ & $1.9 \%$ & $4.4 \%$ \\
\hline Volatility & $23.3 \%$ & $12.5 \%$ & $13.7 \%$ & $14.8 \%$ & $27.3 \%$ & $23.8 \%$ & $21.1 \%$ & $16.4 \%$ & $22.6 \%$ \\
\hline Sharpe & 0.23 & 0.26 & 0.51 & 0.13 & 0.68 & 0.15 & 0.38 & 0.11 & 0.20 \\
\hline Beta & 0.00 & 0.00 & 0.00 & 0.00 & 0.00 & 0.00 & 0.00 & 0.00 & 0.00 \\
\hline Alpha & $5.2 \%$ & $3.3 \%$ & $7.0 \%$ & $1.9 \%$ & $18.6 \%$ & $3.6 \%$ & $8.0 \%$ & $1.9 \%$ & $4.4 \%$ \\
\hline t-value & 0.95 & 1.10 & 2.15 & 0.53 & 2.88 & 0.63 & 1.60 & 0.48 & 0.83 \\
\hline
\end{tabular}

This table shows VOL and BAB factors within each sector. Due to the lower number of stocks per sector, VOL and $\mathrm{BAB}$ factors are created based on single sorts using again past 36-month volatility (beta) and the 30th and 70th percentiles as breakpoints. We use the 11 main sectors as defined by the Global Industry Classification Standard (GICS) classification, but merge two sectors with a low number of stocks with related sectors: real estate (GIGS sector code 60) with financials (40), and communication services (50) with information technology (45). The VOL and BETA factors for each sector are made beta neutral, by levering up the long leg and levering down the short leg to full-sample markets betas of 1 each

Table 1. The ex post volatilities of the decile portfolios show a monotonic increase from less than $25 \%$ per annum for the lowest-risk portfolio (D1) to over 35\% for the highest-risk portfolio (D10), which implies that the sort on ex ante volatility is effective. Looking at the ex post returns, we observe that the least risky portfolio has the highest return, while the most risky portfolio has the lowest return. The combined result is an annualized Sharpe ratio of 0.51 for D1 versus a Sharpe ratio of 0.00 for D10. Adjusting for market beta we find a statistically significant annualized alpha of $5.7 \%$ for D1 and an even more significant alpha of $-10.4 \%$ for D10. Thus, the D1-D10 alpha spread amounts to no less than $16.1 \%$. These results are fully consistent with the findings of Blitz and van Vliet (2007) for the US, Europe, and Japan, who document a similar inverse relation between risk and return, and also a particularly big negative alpha for the most risky stocks.

Panel B of Table 1 reports the results for the portfolios sorted on market beta. The beta-sorted portfolios show a generally similar performance pattern as the volatilitysorted portfolios, but less pronounced. The top decile has an alpha of just $2.3 \%$, which is not even statistically significant. The bottom decile is still significant, with an alpha of $-7.4 \%$, resulting in an also significant D1-D10 alpha spread of $9.7 \%$. Intriguingly, it is the third decile portfolio which exhibits the highest return, Sharpe ratio and alpha, closely followed by the second decile portfolio. For the US, Europe, and Japan, Blitz and van Vliet (2007) also find that volatility is more powerful than beta, but the gap between the two metrics is particularly large in China. Since the beta of a stock is equal to its volatility times its correlation with the market divided by a constant, the volatility of the market, the differences between sorts on beta and volatility come from correlations. In unreported tests, we find that stocks with very low correlations exhibit particularly poor performance in China. In other words, by sorting on beta we effectively contaminate a powerful metric, volatility, with a metric that only detracts from performance, correlation.

The results for Fama-French style $(2 \times 3)$ VOL and BETA factors, as described in the methodology section, are reported in Panels $\mathrm{C}$ and D of Table 1. The VOL factor generates a highly significant premium of $9.1 \%$ per annum. The Sharpe ratio of the VOL factor is 0.88 , which is higher than the 0.61 Sharpe ratio of the D1-D10 portfolio. Besides not being in line with the Fama-French factor methodology, the D1-D10 portfolio also has a negative market beta of -0.36 which lowers its raw return and Sharpe ratio. Consistent with the findings in Panels A and B of Table 1, the BETA factor is a bit weaker, with a premium of $6.0 \%$ per annum and a Sharpe ratio of 0.58. By construction, the VOL and BETA factors have the same return as alpha, since their betas are zero. The t-statistic of the volatility factor is 3.72 , and for the beta factor it is 2.43 .

Table 2 reports the VOL and BETA premium within each sector, as described in the methodology section. The VOL and BETA premiums turn out to be positive in each sector, without a single exception. The VOL premium is even statistically significant in the majority of sectors. The dominance 
Table 3 Comparison with other factors

Table 4 Controlling for other factors

\begin{tabular}{lccccccc}
\hline & RM-RF & SMB & HML & CMA & RMW & UMD & VOL \\
\hline Return & $8.8 \%$ & $4.5 \%$ & $10.2 \%$ & $2.1 \%$ & $0.9 \%$ & $-1.0 \%$ & $9.1 \%$ \\
Volatility & $29.0 \%$ & $16.3 \%$ & $15.0 \%$ & $8.2 \%$ & $9.0 \%$ & $13.7 \%$ & $10.3 \%$ \\
Sharpe & 0.31 & 0.28 & 0.68 & 0.25 & 0.10 & -0.07 & 0.88 \\
Beta & 1.00 & 0.12 & 0.06 & -0.07 & -0.01 & -0.08 & 0.00 \\
Alpha & - & $3.6 \%$ & $9.7 \%$ & $2.6 \%$ & $1.0 \%$ & $-0.3 \%$ & $9.1 \%$ \\
$t$-value & - & 0.95 & 2.75 & 1.39 & 0.45 & -0.09 & 3.72 \\
\hline
\end{tabular}

This table shows the annualized return, volatility, and Sharpe ratio for the market (RM-RF), size (SMB), value (HML), profitability (RMW), investment (CMA), momentum (WML), and volatility (VOL) factors for the Chinese A-share market over the December 2000-December 2018. For all factors besides the market, we also compute the realized CAPM beta and alpha (and the associated $t$-value)

\begin{tabular}{|c|c|c|c|c|c|c|c|c|c|c|c|}
\hline \multicolumn{5}{|c|}{ Panel A: Value factor (HML) based on BtM } & \multirow[b]{2}{*}{ ALL } & \multicolumn{5}{|c|}{ Panel B: Value factor (VMG) based on EtP } & \multirow[b]{2}{*}{ ALL } \\
\hline & CAPM & $3 \mathrm{FM}$ & $5 \mathrm{FM}$ & $6 \mathrm{FM}$ & & & CAPM & 3FM & $5 \mathrm{FM}$ & $6 \mathrm{FM}$ & \\
\hline Alpha & $9.1 \%$ & $8.9 \%$ & $8.7 \%$ & $8.0 \%$ & $8.2 \%$ & Alpha & $9.1 \%$ & $6.8 \%$ & $6.6 \%$ & $5.2 \%$ & $5.3 \%$ \\
\hline$t$-value & 3.72 & 3.95 & 3.88 & 3.51 & 3.49 & $\mathrm{t}$-value & 3.72 & 2.91 & 2.96 & 2.27 & 2.27 \\
\hline RM-RF & 0.00 & 0.02 & 0.03 & 0.04 & 0.04 & RM-RF & 0.00 & 0.03 & 0.03 & 0.03 & 0.03 \\
\hline$t$-value & 0.00 & 1.06 & 1.53 & 1.59 & 1.60 & $\mathrm{t}$-value & 0.00 & 1.24 & 1.33 & 1.57 & 1.58 \\
\hline SMB & - & -0.25 & -0.19 & -0.15 & -0.15 & SMB & - & -0.17 & -0.14 & -0.06 & -0.06 \\
\hline$t$-value & - & -6.30 & -3.94 & -2.97 & -2.93 & t-value & - & -3.60 & -2.82 & -1.06 & -1.05 \\
\hline HML & - & 0.12 & 0.04 & 0.11 & 0.11 & VMG & - & 0.24 & 0.21 & 0.32 & 0.32 \\
\hline$t$-value & - & 2.74 & 0.82 & 1.70 & 1.70 & t-value & - & 3.96 & 3.21 & 4.26 & 4.25 \\
\hline CMA & - & - & 0.20 & 0.20 & 0.21 & CMA & - & - & 0.07 & 0.04 & 0.04 \\
\hline$t$-value & - & - & 2.00 & 2.08 & 2.10 & t-value & - & - & 0.63 & 0.34 & 0.36 \\
\hline RMW & - & - & 0.16 & 0.15 & 0.15 & RMW & - & - & 0.20 & 0.28 & 0.28 \\
\hline$t$-value & - & - & 1.84 & 1.78 & 1.73 & t-value & - & - & 2.89 & 3.84 & 3.77 \\
\hline UMD & - & - & - & 0.11 & 0.11 & UMD & - & - & - & 0.16 & 0.17 \\
\hline$t$-value & - & - & - & 1.80 & 1.82 & $\mathrm{t}$-value & - & - & - & 2.93 & 2.93 \\
\hline BONDS & & & & & -0.06 & BONDS & & & & & -0.04 \\
\hline$t$-value & & & & & -0.37 & $t$-value & & & & & -0.26 \\
\hline Adj. $R^{2}$ & $0 \%$ & $19 \%$ & $21 \%$ & $22 \%$ & $21 \%$ & Adj. $R^{2}$ & $0 \%$ & $22 \%$ & $24 \%$ & $27 \%$ & $27 \%$ \\
\hline
\end{tabular}

This table presents the results of a series of spanning tests where we regress VOL factor returns on the CAPM, Fama and French (1993) three-factor model (3FM), Fama and French (2015) five-factor model $(5 \mathrm{FM})$, the $5 \mathrm{FM}$ augmented with a momentum factor to a six-factor model $(6 \mathrm{FM})$, and the 6FM augmented with a Bond factor (ALL). The Bond factor is based on the excess return of the iBoxx ABF China Government Index. Panel A shows the results for the standard value factor (HML) based on the book-to-market ratio (BtM), while Panel B shows results for a value factor (VMG) based on the earnings-to-price (EtP). The sample period runs from December 2000 to December 2018 of volatility over beta is reconfirmed by the finding that the VOL premium is larger than the BETA premium in 8 out of 9 sectors. In the rest of the paper, we will focus on the volatility factor.

In Table 3, we compare the VOL premium with the wellknown and widely used factor premiums of Fama and French (2015) and Carhart (1997). The VOL premium turns out to be the strongest of all on a risk-adjusted basis, i.e., in terms of Sharpe ratio or t-statistic of the alpha. Only the value premium, HML, has a slightly higher raw return of $10.2 \%$ (versus $9.1 \%$ for VOL), but with higher risk. Together, the low-risk and value premiums are the strongest factors in
China. The size premium, SMB, is positive but not even half as strong, while the profitability, investment, and momentum premiums appear to be completely absent. These findings are consistent with Cheung et al. (2015), Guo et al. (2017), and Hsu et al. (2018). The Sharpe ratios for the various factors in China are summarized in Fig. 1.

The low-risk premium in the US equity market is dismissed by Novy-Marx (2014) and Fama and French (2016), who argue that it is subsumed by a profitability factor in time-series regressions. Blitz and Vidojevic (2017) challenge this conclusion by showing that cross-sectional Fama and MacBeth (1973) tests do support the existence of a 
Table 5 Correlation with other countries/regions

\begin{tabular}{lccrrl}
\hline & China & US & Europe & Japan & Asia Pacific \\
\hline Return & $9.1 \%$ & $6.7 \%$ & $8.0 \%$ & $5.6 \%$ & $10.2 \%$ \\
Volatility & $10.3 \%$ & $11.0 \%$ & $10.6 \%$ & $11.5 \%$ & $12.6 \%$ \\
Sharpe & 0.88 & 0.61 & 0.75 & 0.48 & 0.81 \\
Cor. with China & - & 0.05 & 0.03 & -0.02 & 0.10 \\
\hline
\end{tabular}

This table shows the annualized return, volatility, and Sharpe ratio for the VOL factor in China and similarly constructed VOL factors for the US, Europe, Japan, and Asia Pacific excluding Japan regions and the correlation of the VOL factor in these regions with the VOL factor in China. The sample period runs from December 2000 to December 2018

distinct low-risk anomaly. In addition, Blitz et al. (2020a) find that the time-series results are fully driven by the short legs of the low-risk and profitability factors, and that the long low-risk portfolio is not subsumed by the long highprofitability portfolio.

In Table 4, we show that the VOL premium in China is not subsumed by other factors in time-series regressions. Controlling for the market, size, value, profitability, investment, and momentum, hardly affects the alpha, with $8.0 \%$ out of the raw $9.1 \%$ remaining unexplained. There are two reasons for this very different conclusion compared to the US. First, the loadings on the Fama-French-Carhart factors are relatively low, in particular the loading on the profitability factor which is crucial for the US results. Second, as shown in Table 3, the profitability factor is simply too weak in China to explain a factor as strong as VOL.

Prior research suggests that the low-risk effect may be explained by an implicit exposure to interest rate changes (cf., Baker and Wurgler 2012; Muijsson et al. 2015; and Blitz 2020). De Franco et al. (2017) formally examine this issue for the US and conclude that although low-risk stocks have a statistically significant exposure to interest rate risk, this only explains a very small part of their alpha. We also analyze this relationship for the Chinese market by adding a bond factor (the excess return of the iBoxx ABF China Government Index) to the spanning tests in Table 4. ${ }^{7}$ However, our conclusions remain unchanged as the VOL factor in China has a negligible loading on the bond factor. Therefore, we conclude that interest rate risk cannot explain the lowrisk effect for China A shares.

Liu et al. (2019) propose a 3 -factor model for China, consisting of market, size, and value factors, which they show explains the short-term iVol and MAX anomalies. Importantly, their value factor departs from the HML factor of Fama and French (1993) by using the earnings-to-price ratio (EtP) instead of the book-to-market ratio (BtM), based on

\footnotetext{
$\overline{7}$ We are grateful to an anonymous referee for this suggestion.
}

their finding that EtP is a much more powerful valuation metric in China than BtM. We therefore repeat the spanning tests using an EtP value factor. The results are reported in Panel B of Table 4. Although the VOL factor has a significant loading on the alternative value factor, the alpha is only partially explained. The bigger part of the VOL alpha remains unexplained and statistically significant.

In Table 5, we compare the VOL factor in China with the value-weighted $2 \times 3$ VOL factors for the US, Europe, Japan, and Asia Pacific excluding Japan regions as used in Blitz et al. (2020a). ${ }^{8}$ The comparison shows that China is among the markets in which the VOL factor is most powerful. Also, the VOL factor's performance in China is practically uncorrelated with the VOL factors in other regions. The low correlations between the VOL factor in China and other regions also imply that they are not driven by some shared global systematic risk factor, which argues against risk-based explanations while supporting explanations based on mispricing. Furthermore, the VOL factor in China offers a distinct source of alpha that is not already captured by VOL factors from other regions.

We further examine the robustness of the VOL factor in China by varying the lookback period for measuring volatility, by extending the holding period from one month up to 60 months, by breaking the VOL factor down into its separate large-cap and small-cap components, and by looking at performance over subsamples. Panel A of Table 6 shows that there is a similar-sized VOL premium for volatility measured over the past 20 days, the past 52 weeks, the past 36 months, and the past 60 months. The alphas show no clear pattern along the lookback horizon, amounting to $9.3 \%, 10.1 \%, 9.1 \%$, and $9.3 \%$, respectively. The t-values are all well above 3 , ranging between 3.40 and 4.38. Thus, the factor is highly robust to the choice for the lookback period. To investigate the robustness of the VOL factor for longer holding periods, we follow the overlapping portfolio approach of Jegadeesh and Titman (1993, 2001). With this approach, the strategies hold a series of portfolios, in any given month, that are selected in the current month as well as in the previous $\mathrm{K}-1$ months, where $\mathrm{K}$ is the holding period. Panel B shows that the VOL factor is robust to holding periods up to 60 month. The alphas for 1-, 6-, and 12-month holding periods are similar and range from 9.1\% to $9.3 \%$, while for the 36- and 60-month holding period, the alphas slightly decrease to $8.0 \%$ and $7.1 . \%$, respectively. The $\mathrm{t}$-values, however, are all above 3 and range between 3.72 and 4.01. This robustness is not surprising as the 36-month lookback period leads to a persistent volatility estimate that results in low turnover. Next, we make a breakdown of the

\footnotetext{
8 The sample and factor construction is described in Hanauer and Windmüller (2020).
} 
Table 6 Robustness

Panel A: Estimation period VOL factor

\begin{tabular}{lcccc}
\hline & 20 -day & 52-week & 36 -month & 60 -month \\
\hline Alpha & $9.3 \%$ & $10.1 \%$ & $9.1 \%$ & $9.3 \%$ \\
Volatility & $11.6 \%$ & $11.0 \%$ & $10.3 \%$ & $8.9 \%$ \\
t-value & 3.40 & 3.87 & 3.72 & 4.38 \\
Sharpe & 0.80 & 0.92 & 0.88 & 1.04 \\
\hline Panel B: Holding period VOL factor & & & 36 -month \\
\hline & 1-month & 6 -month & 12 -month & $8.0 \%$ \\
Alpha & $9.1 \%$ & $9.3 \%$ & $9.1 \%$ & $8.5 \%$ \\
Volatility & $10.3 \%$ & $9.9 \%$ & $9.6 \%$ & 3.99 \\
t-value & 3.72 & 3.94 & 4.01 & 0.94 \\
Sharpe & 0.88 & 0.93 & 0.95 & $7.1 \%$ \\
\hline
\end{tabular}

Panel C: Large- and small-cap component of VOL factor

\begin{tabular}{|c|c|c|c|c|c|}
\hline & VOL & $\mathrm{VOL}_{\mathrm{B}}$ & $\mathrm{VOL}_{\mathrm{S}}$ & & \\
\hline Alpha & $9.1 \%$ & $11.9 \%$ & $6.4 \%$ & & \\
\hline Volatility & $10.3 \%$ & $16.0 \%$ & $7.8 \%$ & & \\
\hline t-value & 3.72 & 3.14 & 3.47 & & \\
\hline$\underline{\text { Sharpe }}$ & 0.88 & 0.74 & 0.82 & & \\
\hline \multicolumn{6}{|c|}{ Panel D: Subsamples VOL factor } \\
\hline & $00-05$ & $06-10$ & $10-15$ & $15-18$ & Full \\
\hline Return & $5.0 \%$ & $5.0 \%$ & $12.7 \%$ & $17.2 \%$ & $9.1 \%$ \\
\hline Volatility & $7.5 \%$ & $11.8 \%$ & $12.1 \%$ & $8.5 \%$ & $10.3 \%$ \\
\hline Sharpe & 0.66 & 0.42 & 1.05 & 2.02 & 0.88 \\
\hline Beta & 0.04 & 0.01 & -0.03 & 0.02 & 0.00 \\
\hline Alpha & $5.4 \%$ & $4.7 \%$ & $13.0 \%$ & $17.4 \%$ & $9.1 \%$ \\
\hline t-value & 1.60 & 0.85 & 2.37 & 3.46 & 3.72 \\
\hline
\end{tabular}

This table shows the annualized alpha, the associated volatility and $t$-value, and Sharpe ratio for the volatility (VOL) factor constructed based on various past volatility estimates (Panel A), for various holding periods (Panel B), for the VOL factor broken down into its separate large-cap and small-cap components (Panel C), and for several subperiods (Panel D). Panel D shows additionally also the annualized return and realized CAPM beta. The full sample period runs from December 2000 to December 2018

VOL factor into the large-cap and small-cap component. Panel $\mathrm{C}$ shows that both components of the VOL factor are strong. The large-cap component has a higher raw return, but the small-cap component has a higher risk-adjusted return. Based on these results, we conclude that the volatility effect in China is not driven by small- or micro-cap stocks. Finally, we split the sample period into four distinct subperiods. Panel D of Table 6 shows that the VOL factor is positive in every subperiod, which further confirms the robustness of the factor. Contrary to the popular notion that anomalies may disappear once everyone knows about them (see, e.g., McLean and Pontiff 2016), the VOL factor only appears to have become stronger over time.

Novy-Marx and Velikov (2016) find that anomalies that involve a low turnover can usually be exploited successfully after costs, while anomalies that require a high turnover generally do not survive after costs. In light of their findings, it is questionable how much performance will be left after costs for low-risk strategies with a high turnover, such as the iVol and MAX strategies that are based on lookback periods of just one month. However, the turnover of the VOL factor in this study is much lower, since it uses a 36-month lookback period. As a result, stocks are held for more than a year on average and economic and statistical significant VOL premiums exists for holding periods at least up to 60 months. Another potential concern is the finding of Hou et al. (2020), who find that many anomalies disappear after excluding illiquid micro-cap stocks and using value-weighting instead of equal-weighting. However, this concern also does not apply to the VOL factor, which is value-weighted, constructed on a universe which excludes micro-caps, and consisting of separate large-cap and small-cap components 
that are both strong, as shown in Panel C of Table 6. Thus, the low-risk anomaly exhibits good investability properties.

\section{Summary}

This paper shows that the low-risk anomaly is strongly present in the local China A-share market. Contrary to the predictions of prevailing theoretical asset pricing models, the least risky stocks in China exhibit the highest returns, while the most risky stocks earn the lowest returns. The main driver of the low-risk anomaly in China is volatility, and not beta. These findings are highly consistent with previous empirical evidence for the US and international developed and emerging equity markets. Our findings are robust across sectors and over time. These 'out-of-sample' results also help to better understand the low-risk anomaly. A Fama-French style VOL factor cannot be explained by the established Fama-French-Carhart factors, and even shows a stronger risk-adjusted performance than each of these other factors. Altogether, our results imply that the volatility effect is a highly pervasive phenomenon, and that explanations should be able to account for its presence in highly institutionalized markets such as the US, but also in the Chinese market where trading is dominated by private investors. Finally, the VOL factor exhibits good practical investability properties, as it involves a low turnover and is also powerful when applied to only the largest and most liquid stocks. We acknowledge that the inclusion of China A shares to MSCI Emerging Market index starting in 2018 might affect the future behavior of local asset prices. ${ }^{9}$ With some years of additional data, such an examination is certainly an interesting topic for future research.

Acknowledgements The views expressed in this paper are solely those of the authors and not necessarily shared by their respective institutions. The authors are grateful to Laurens Swinkels, Weili Zhou, and an anonymous referee for valuable feedback.

Funding Open Access funding enabled and organized by Projekt DEAL.

Open Access This article is licensed under a Creative Commons Attribution 4.0 International License, which permits use, sharing, adaptation, distribution and reproduction in any medium or format, as long as you give appropriate credit to the original author(s) and the source, provide a link to the Creative Commons licence, and indicate if changes were made. The images or other third party material in this article are included in the article's Creative Commons licence, unless indicated otherwise in a credit line to the material. If material is not included in the article's Creative Commons licence and your intended use is not permitted by statutory regulation or exceeds the permitted use, you will

\footnotetext{
${ }_{9}$ We are grateful to an anonymous referee for raising this point.
}

need to obtain permission directly from the copyright holder. To view a copy of this licence, visit http://creativecommons.org/licenses/by/4.0/.

\section{References}

Ang, A., R.J. Hodrick, Y. Xing, and X. Zhang. 2006. The cross-section of volatility and expected returns. Journal of Finance 61(1): 259-299.

Ang, A., R.J. Hodrick, Y. Xing, and X. Zhang. 2009. High idiosyncratic volatility and low returns: International and further US evidence. Journal of Financial Economics 91(1): 1-23.

Asness, C.S., A. Frazzini, and L.H. Pedersen. 2014. Low-risk investing without industry bets. Financial Analysts Journal 70(4): 24-41.

Baker, M., B. Bradley, and R. Taliaferro. 2014. The low-risk anomaly: A decomposition into micro and macro effects. Financial Analysts Journal 70(2): 43-58.

Baker, M., B. Bradley, and J. Wurgler. 2011. Benchmarks as limits to arbitrage: Understanding the low-volatility anomaly. Financial Analysts Journal 67(1): 40-54.

Baker, N.L., and R.A. Haugen. 2012. Low risk stocks outperform within all observable markets of the world. SSRN working paper no. 2055431.

Baker, M., and J. Wurgler. 2012. Comovement and predictability relationships between bonds and the cross-section of stocks. Review of Asset Pricing Studies 2(1): 57-87.

Bali, T.G., S.J. Brown, S. Murray, and Y. Tang. 2017. A lotterydemand-based explanation of the beta anomaly. Journal of Financial and Quantitative Analysis 52(6): 2369-2397.

Bali, T.G., N. Cakici, and R.F. Whitelaw. 2011. Maxing out: Stocks as lotteries and the cross-section of expected returns. Journal of Financial Economics 99(2): 427-446.

Barberis, N., and M. Huang. 2008. Stocks as lotteries: The implications of probability weighting for security prices. American Economic Review 98(5): 2066-2100.

Black, F., M.C. Jensen, and M. Scholes. 1972. The capital asset pricing model: Some empirical tests. Studies in the Theory of Capital Markets 81(3): 79-121.

Blitz, D. 2020. The risk-free asset implied by the market: Medium-term bonds instead of short-term bills. Journal of Portfolio Management 46(8): 120-132.

Blitz, D., G. Baltussen, and P. van Vliet. 2020a. When factors drop their shorts. Financial Analysts Journal 76(4): 73-99.

Blitz, D., E. Falkenstein, and P. van Vliet. 2014. Explanations for the volatility effect: An overview based on the CAPM assumptions. Journal of Portfolio Management 40(3): 61-76.

Blitz, D., J. Pang, and P. Van Vliet. 2013. The volatility effect in emerging markets. Emerging Markets Review 16: 31-45.

Blitz, D., and M. Vidojevic. 2017. The profitability of low-volatility. Journal of Empirical Finance 43: 33-42.

Blitz, D., and P. van Vliet. 2007. The volatility effect. Journal of Portfolio Management 34(1): 102-113.

Blitz, D., P. van Vliet, and G. Baltussen. 2020b. The volatility effect revisited. Journal of Portfolio Management 46(2): 45-63.

Buehlmaier, M.M., and K.P. Wong. 2020. Should investors join the index revolution? Evidence from around the world. Journal of Asset Management 21(3): 192-218.

Cakici, N., K. Chan, and K. Topyan. 2017. Cross-sectional stock return predictability in China. European Journal of Finance 23(7-9): $1-25$.

Carhart, M. 1997. On persistence in mutual fund performance. Journal of Finance 51(1): 57-82.

Chen, X., K.A. Kim, T. Yao, and T. Yu. 2010. On the predictability of Chinese stock returns. Pacific-Basin Finance Journal 18(4): 403-425. 
Chen, A., E. Pong, and Y. Wang. 2018. Accessing the China A-shares market via minimum-variance investing. Journal of Portfolio Management 45(1): 106-117.

Cheema, M.A., G. Nartea, and Y. Man. 2018. Maxing out in China: Optimism or attention? SSRN working paper No. 3176864 (forthcoming International Review of Finance)

Cheung, C., G. Hoguet, and S. Ng. 2015. Value, size, momentum, dividend yield, and volatility in China's A-share market. Journal of Portfolio Management 41(5): 57-70.

Clarke, R., H. De Silva, and S. Thorley. 2006. Minimum-variance portfolios in the US equity market. Journal of Portfolio Management 33(1): 10-24.

Clarke, R., H. De Silva, and S. Thorley. 2011. Minimum-variance portfolio composition. Journal of Portfolio Management 37(2): 31-45.

De Franco, C., B. Monnier, and K. Rulik. 2017. Interest rate exposure of volatility portfolios. The Journal of Index Investing 8(2): 53-67.

Eun, C.S., and W. Huang. 2007. Asset pricing in China's domestic stock markets: Is there a logic?. Pacific Basin Finance Journal 15(5): 452-480.

Fama, E.F., and K.R. French. 1992. The cross-section of expected stock returns. Journal of Finance 47(2): 427-465.

Fama, E.F., and K.R. French. 1993. Common risk factors in the returns on stocks and bonds. Journal of Financial Economics 33(1): 3-56.

Fama, E.F., and K.R. French. 2012. Size, value, and momentum in international stock returns. Journal of Financial Economics 105(3): 457-472.

Fama, E.F., and K.R. French. 2015. A five-factor asset pricing model. Journal of Financial Economics 116(1): 1-22.

Fama, E.F., and K.R. French. 2016. Dissecting anomalies with a fivefactor model. Review of Financial Studies 29(1): 69-103.

Fama, E.F., and K.R. French. 2017. International tests of a five-factor asset pricing model. Journal of Financial Economics 123(3): 441-463.

Fama, E.F., and J.D. MacBeth. 1973. Risk, return, and equilibrium: Empirical tests. Journal of Political Economy 81(3): 607-636.

Frazzini, A., and L.H. Pedersen. 2014. Betting against beta. Journal of Financial Economics 111(1): 1-25.

Guo, B., W. Zhang, Y. Zhang, and H. Zhang. 2017. The five-factor asset pricing model tests for the Chinese stock market. Pacific-Basin Finance Journal 43: 84-106.

Han, X., and Y. Li. 2017. Can investor sentiment be a momentum time-series predictor? Evidence from China. Journal of Empirical Finance 42: 212-239. https://doi.org/10.1016/j.jempfin.2017. 04.001.

Han, X., K. Li, and Y. Li. 2020. Investor overconfidence and the security market line: New evidence from China. Journal of Economic Dynamics and Control 117: 103961.

Hanauer, M.X., and S. Windmüller. 2020. Enhanced momentum strategies. SSRN working paper No. 3437919.

Haugen, R.A., and N.L. Baker. 1991. The efficient market inefficiency of capitalization-weighted stock portfolios. Journal of Portfolio Management 17(3): 35-40.

Haugen, R.A., and N.L. Baker. 2010. Case closed. In Handbook of Portfolio Construction (pp. 601-619). Springer, Boston, MA

Haugen, R.A., and A.J. Heins. 1975. Risk and the rate of return on financial assets: Some old wine in new bottles. Journal of Financial and Quantitative Analysis 10(5): 775-784.

Hilliard, J., and H. Zhang. 2015. Size and price-to-book effects: Evidence from the Chinese stock markets. Pacific-Basin Finance Journal 32: 40-55.

Hou, K., C. Xue, and L. Zhang. 2020. Replicating anomalies. Review of Financial Studies 33(5): 2019-2133.

Hsu, J., V. Viswanathan, M. Wang, and P. Wool. 2018. Anomalies in Chinese A-shares. Journal of Portfolio Management 44(7): 108-123.
Hu, G. X., J. Pan, and J. Wang. 2018. Chinese capital market: An empirical overview. NBER working Paper No. 24346 (forthcoming Critical Finance Review).

Jansen, M., L. Swinkels, and W. Zhou. 2021. Anomalies in the China A-share market. SSRN working paper No. 3437919.

Jegadeesh, N., and S. Titman. 1993. Returns to buying winners and selling losers: Implications for stock market efficiency. Journal of Finance 48(1): 65-91.

Jegadeesh, N., and S. Titman. 2001. Profitability of momentum strategies: An evaluation of alternative explanations. Journal of Finance 56(2): 699-720.

Lewellen, J., S. Nagel, and J. Shanken. 2010. A skeptical appraisal of asset pricing tests. Journal of Financial Economics 96(2): $175-194$.

Liu, J., R.F. Stambaugh, and Y. Yuan. 2019. Size and value in China. Journal of Financial Economics 134(1): 48-69.

Long, H., A. Zaremba, and Y. Jiang. 2019. Beware of the crash risk: Tail beta and the cross-section of stock returns in China. Applied Economics 51(44): 4870-4881.

McLean, R.D., and J. Pontiff. 2016. Does academic research destroy stock return predictability?. Journal of Finance 71(1): 5-32.

Miller, M.H., and M. Scholes. 1972. Rates of return in relation to risk: A reexamination of some recent findings. Studies in the theory of capital markets, 47-78. New York: Praeger.

Muijsson, C., E. Fishwick, and S. Satchell. 2015. The low beta anomaly and interest rates. Risk-based and factor investing, 305-328. Elsevier.

Novy-Marx, R. 2014. Understanding defensive equity. NBER working paper no. 20591.

Novy-Marx, R., and M. Velikov. 2016. A taxonomy of anomalies and their trading costs. Review of Financial Studies 29(1): 104-147.

Russo, A. 2016. Low-risk equity investment-From theory to practice. Journal of Asset Management 17(4): 264-279.

Seiler, M.J., D.M. Harrison, P. Van Vliet, and K.C. Yeung. 2005. Return characteristics of state-owned and non-state-owned Chinese A shares. Financial Review 40(4): 533-548.

Su, D., and B.M. Fleisher. 1999. Why does return volatility differ in Chinese stock markets?. Pacific-Basin Finance Journal 7(5): 557-586.

Tan, L., T.C. Chiang, J.R. Mason, and E. Nelling. 2008. Herding behavior in Chinese stock markets: An examination of A and B shares. Pacific-Basin Finance Journal 16(1-2): 61-77.

Walkshäusl, C. 2014. International low-risk investing. Journal of Portfolio Management 41(1): 45-56.

Wang, F., and Y. Xu. 2004. What determines Chinese stock returns?. Financial Analysts Journal 60(6): 65-77.

Wang, Y., and A. Di Iorio. 2007. The cross section of expected stock returns in the Chinese A-share market. Global Finance Journal 17(3): 335-349.

Wong, K.A., R.S.K. Tan, and W. Liu. 2006. The cross-section of stock returns on the Shanghai Stock Exchange. Review of Quantitative Finance and Accounting 26(1): 23-39.

Publisher's Note Springer Nature remains neutral with regard to jurisdictional claims in published maps and institutional affiliations.

David Blitz Chief Researcher, has been instrumental in the design and development of Robeco's quantitative investment strategies. He chairs the two committees that govern new strategies and model enhancements. David has published dozens of papers in peer-reviewed academic journals, such as Journal of Empirical Finance, Journal of Portfolio Management and European Financial Management. He started his career in the investment industry at Robeco in 1995 . He holds a PhD 
in Finance and a Master's in Econometrics (cum laude) from Erasmus University Rotterdam

Matthias X. Hanauer is a Researcher at Robeco's Quant Selection Research team. His areas of expertise include international factor premia, stock selection, and portfolio construction research. Matthias joined Robeco in 2014 after submitting his doctoral dissertation at Technische Universität München (TUM), where he also holds a parttime position. He has published his academic work in various peerreviewed journals and presented at top finance conferences. Matthias holds a PhD in Finance and a Master's in Business Administration from TUM and is a CFA® charterholder.
Pim van Vliet is Lead Portfolio Manager Conservative Equities and Co-Head of Robeco's Quantitative Equities department. He specializes in low-volatility investing, asset pricing, and quantitative finance. He is the author of numerous academic research papers including publications in the Journal of Financial Economics, the Journal of Banking and Finance, Management Science, the Journal of Portfolio Management. Pim is a guest lecturer at several universities, author of an investment book and speaker at international seminars. He became Portfolio Manager in 2010. Pim joined Robeco in 2005 as a Researcher with responsibility for asset allocation research. Pim holds a $\mathrm{PhD}$ and a Master's cum laude in Financial and Business Economics from Erasmus University Rotterdam. 